\title{
Association of Somatotrophinomas with Loss of Alleles on Chromosome 11 and with gsp Mutations
}

\author{
R. V. Thakker, ${ }^{\star}$ M. A. Pook, ${ }^{*}$ C. Wooding, ${ }^{*}$ M. Boscaro, ${ }^{\star}$ M. Scanarini, ${ }^{\star}$ and R. N. Clayton ${ }^{\star}$ \\ ${ }^{*}$ M.R.C. Molecular Medicine Group, Royal Postgraduate Medical School, Hammersmith Hospital, London W12 0NN, United \\ Kingdom; ${ }^{\ddagger}$ Department of Endocrinology \& Neurosurgery, University of Padua, Italy; ${ }^{\S}$ Department of Endocrinology \& Diabetes \\ Mellitus, North Staffordshire Royal Infirmary, Stoke-on-Trent, United Kingdom
}

\begin{abstract}
The molecular pathology of somatotrophinomas has been investigated by a combined search for dominant mutations of the gene encoding the $G_{s} \alpha$ protein and for recessive mutations involving chromosome 11q13, which contains the gene causing multiple endocrine neoplasia type 1 (MEN1). Somatotrophinomas and peripheral leukocytes were obtained from thirteen patients with acromegaly; one patient also suffered from MEN1. Five DNA probes identifying restriction fragment length polymorphisms from $11 q$ revealed allele loss in pituitary tumors from five (four non-MEN1 and one MEN1) patients. Deletion mapping revealed that the region of allele loss common to the somatotrophinomas involved 11q13. An analysis for similar allelic deletions at 12 other loci from chromosomes 1-5, 7-9, 12-14, and 17 did not reveal generalized allele loss in the somatotrophinomas. These results, which represent the first report of chromosome 11 allele loss occurring in non-MEN1 somatotrophinomas, indicate that a recessive oncogene on $11 q 13$ is specifically involved in the monoclonal development of somatotrophinomas. In addition $G_{s} \alpha$ mutations were detected in two non-MEN1 somatotrophinomas, one of which also revealed allele loss of chromosome 11 . Thus, our results reveal that the development of somatotrophinomas is associated with alterations in both dominant and recessive oncogenes and further characterization of these genetic abnormalities will help to elucidate the multistep etiology and progression of somatotrophinomas. (J. Clin. Invest. 1993. 2815-2821.) Key words: tumor suppressor genes • tumorigenesis • acromegaly
\end{abstract}

\section{Introduction}

The development of tumors may be associated with an activation of dominant oncogenes or an inactivation of recessive oncogenes $(1,2)$, which are also referred to as anti-oncogenes or tumor suppressor genes (3). A dominantly acting oncogene, due to a point mutation in one copy of the gene encoding the $\alpha$ chain of the guanine nucleotide (GTP) binding subunit of the stimulatory regulator of adenylyl cyclase, referred to as the Gs protein, has been demonstrated to be associated with a subset

Address correspondence to Dr. R. V. Thakker, MRC Molecular Medicine Group, Collier Building, Royal Postgraduate Medical School, Hammersmith Hospital, Du Cane Road, London W12 0NN, United Kingdom.

Received for publication 12 December 1991 and in revised form 19 January 1993.

\section{J. Clin. Invest.}

(C) The American Society for Clinical Investigation, Inc.

$0021-9738 / 93 / 06 / 2815 / 07 \quad \$ 2.00$

Volume 91, June 1993, 2815-2821 of somatotrophinomas, which are growth hormone (GH)-secreting pituitary tumors $(4,5)$. This Gs protein $\alpha$ chain mutation, which is also referred to as a gsp mutation, was found in $40 \%$ of somatotrophinomas (5). In the remaining $60 \%$ of somatotrophinomas abnormalities in other genes are likely to be involved. Somatotrophinomas are known to occur in families either as an isolated autosomal dominant endocrinopathy (6, 7 ), or as part of the autosomal dominant Multiple Endocrine Neoplasia Type 1 (MEN1) ${ }^{1}$ syndrome (8), which is characterized by the combined occurrence of tumors of the parathyroids, the pancreatic islets, and pituitary. The occurrence of such inherited somatotrophinomas suggests that recessively acting tumor suppressor genes, which are particularly involved in hereditary neoplasms such as retinoblastoma (3), may be associated with the etiology of some tumors. In order to localize and establish the role of such tumor suppressor genes in the development of a tumor $(9,10)$, a demonstration of a loss of tumor heterozygosity, revealed by a comparison of leukocyte and tumor alleles, is required. The tumor suppressor gene causing MEN1 has been localized to the pericentromeric region of the long arm of chromosome 11 (11q13) $(11,12)$, but a previous study of 10 somatotrophinomas ( 9 non-MEN1 and 1 MEN1) did not detect allelic deletions involving chromosome 11 (13). This finding contrasts with the observed chromosome 11 allele loss in sporadic non-MEN1 and MEN1 parathyroid tumors (12-14), and it has been proposed that sporadic pituitary tumors may not arise through inactivation of the MEN1 gene (15). In order to investigate this further, we have performed detailed deletion mapping studies using 14 DNA probes from chromosome 11 . Our results indicate that a recessive tumor suppressor oncogene in the 11 q13 region is involved in the monoclonal development of sporadic non-MEN1 and MEN1 somatotrophinomas. Thus, somatotrophinomas may arise through activation of dominant oncogenes $(4,5)$ or through inactivation of recessive tumor suppressor oncogenes.

\section{Methods}

Clinical material. Pituitary tumors and peripheral blood samples were collected from 13 acromegalic patients ( 6 males and 7 females) with an age range of 20 to $65 \mathrm{yr}$ (Table I). Patients 1 to 11 had no clinical history for the other endocrine tumors of the MEN1 syndrome, and biochemical investigations revealed normocalcemia and normal circulating concentrations of parathyroid hormone. In addition, clinical history revealed no evidence for inherited MEN1 tumors among the firstdegree relatives. Patient 12 , who had previously been treated for Conn's syndrome by a unilateral adrenalectomy, suffered from a nodular goiter and insulin-dependent diabetes mellitus; this patient's endo-

1. Abbreviations used in this paper: MEN 1, multiple endocrine neoplasia type 1; PGA, pepsinogen; PYGM, phosphorylase glycogen muscle, McArdle syndrome; WT, wild type sequence. 
crine tumors were not typical of MEN1 and this patient was classified in the non-MEN1 group. Patient 13 had primary hyperparathyroidism and a family history of MEN1. Additional clinical, biochemical, histological, and immunocytochemistry findings for each patient are shown in Table I. The pituitary tumor tissue was obtained at the time of surgery and stored at $-70^{\circ} \mathrm{C}$ and the venous blood samples were collected in tubes containing EDTA $(0.5 \mathrm{M}$ pH 8.0) and kept frozen at $-70^{\circ} \mathrm{C}$.

DNA hybridization analysis. DNA from leukocytes and tumors was prepared by standard methods $(16,17)$. Leukocyte DNA samples were first assessed at each of the 14 loci on chromosome 11 (Fig. 1) and tumor DNA analysis was performed only at loci which revealed leukocyte heterozygosity. $8 \mu \mathrm{g}$ of DNA was digested to completion with a fourfold excess of one of the following restriction enzymes: BamHI, PstI, PvulI, BglII, TaqI, HaeIII, Hinf I, MspI, or SstII (Boehringer Mannheim Biochemicals, Indianapolis, IN, or Pharmacia Fine Chemicals, Piscataway, NJ). The resulting fragments were separated by $0.8-$ $1.0 \%$ agarose gel electrophoresis and transferred to a nylon membrane (Hybond- N; Amersham Corp., Arlington Heights, IL) by Southern blotting (18). DNA probes were labeled using $\left[\alpha-{ }^{32} \mathrm{P}\right]$ deoxycytidine triphosphate by nick translation (19) or by oligonucleotide-primed synthesis (20). A total of 14 cloned DNA probes from chromosome 11 were used in the study (21) (Fig. 1). Four of these probes-HRAS1 (Harvey ras sarcoma 1 viral-oncogene homologue), INS (insulin), pGBCT2 (calcitonin), and PTH (parathyroid hormone)-were from the short arm; 10 others-PGA (pepsinogen), PYGM (phosphorylase glycogen muscle, McArdle syndrome), apoA1 (apolipoprotein A-I), the oncogene homologues INT2.SS6 (murine mammary-tumor-virusintegration site) and ETS1 (avian erythroblastosis virus E26-1), and the DNA segments D11S149, D11S146, D11S97, D11S144, and D11S147-were from the long arm of chromosome 11. The Southern blot was hybridized as previously described (22), and autoradiography with dual intensifying screens and preflashed Fuji medical x-ray films was performed at $-70^{\circ} \mathrm{C}$ for $5-10 \mathrm{~d}$ to reveal the RFLPs. A loss of alleles in the tumor DNA was scored only if there was absence or a marked reduction in the visually assessed intensity of one of the bands (Fig. 2). The resulting hemizygosity or homozygosity of the tumor DNA was assessed by scanning densitometry (Fig. 3). The DNA probe M27 $\beta$ defining the polymorphic locus DXS255 on the X chromosome (23) was used as an internal standard to quantify the amount of DNA in the leukocyte and tumor lanes, as tumor-associated deletions involving the $\mathrm{X}$ chromosome have not been observed to occur in 33 different types of solid human tumors (24). Densitometric scanning of the autoradiograph was performed $(12,25)$ with use of a dual wavelength TLC scanner (model CS9000; Shimadzu Corp., Tokyo). The intensity $(I)$ of the hybridization signals obtained from the leukocyte DNA $\left(I_{\mathrm{L}}\right)$ and from the tumor DNA $\left(I_{\mathrm{T}}\right)$ were determined for each chromosome 11 probe and for the X chromosome probe DXS255 utilizing the same Southern blot. The ratio in the intensities $\left(I_{\mathrm{r}}\right)$ of the leukocyte DNA and the tumor DNA obtained from the use of the probe DXS255 was utilized to correct for differences in the amount of DNA in each lane: $I_{\mathrm{rt}}$ $=I_{\mathrm{T}}\left(I_{\mathrm{XL}} / I_{\mathrm{XT}}\right)$, where $I_{\mathrm{rT}}$ denotes the intensity of the tumor allele relative to the corresponding leukocyte allele obtained with a probe from chromosome 11 , and $I_{\mathrm{XL}}$ and $I_{\mathrm{XT}}$ denote the intensities obtained with the $\mathrm{X}$ chromosome probe from the leukocyte and tumor DNA, respectively. A ratio of less than 1.5 in the relative intensity of the retained tumor allele to the intensity of the corresponding leukocyte allele $\left(I_{\mathrm{rT}} / I_{\mathrm{L}}\right)$ was indicative of tumor DNA hemizygosity, whereas a ratio exceeding 1.9 was indicative of tumor homozygosity.

Tumor-associated allelic deletions involving other autosomes were assessed by utilizing the 20 DNA probes D1S7, D2S44, D3S44, D4S125, D5S43, D6S44, D7S21, D8S17, D9S7, D10S28, D12S11, D13S37, D14S13, D15S38, D16S137, D17S24, D18S22, D19S20, D20S19, and D21S113, which have been previously localized to chromosomes 1p35-p33, 2p, 3, 4p16.3, 5q35-qter, 6p21-qter, 7p22, 8, 9q34, 10pter-p13, 12q24.3-qter, 13q12-q21, 14q32, 15q, 16, 17q, 18, $19,20 \mathrm{q}$, and $21 \mathrm{q}$, respectively. The somatotrophinomas from 8 patients (patients 3 to 9 and 11 ) were assessed for allelic deletions at each of these 20 autosomal loci. However, in patients $1,2,10,12$, and 13 this analysis was limited to $11,13,17,9$, and 0 loci as sufficient tumor DNA was not available to investigate all of these 20 autosomal loci.

Allele-specific oligonucleotide hybridization. The genomic segments encompassing the two sites of known activating missense mutations of $\mathrm{G}_{\mathrm{s}} \alpha$ (Arg201 in exon 8 and $\mathrm{Gln} 227$ in exon 9) were amplified by the PCR (26), using an automated DNA thermal cycler (combi thermal reactor TR2, Hybaid, Teddington, Middlesex, UK). In order to improve the yield and specificity for these DNA segments, 2 rounds of PCR amplification in which two pairs of $\mathrm{G}_{\mathrm{s}} \alpha$-specific oligonucleotide primers, designated $1 \mathrm{~L}$ and $1 \mathrm{R}$ and $2 \mathrm{~L}$ and $2 \mathrm{R}$, were used. The DNA sequences of these PCR primers were as follows: $1 \mathrm{~L}$ consisted of 5' GCGCTGTGAACACCCCACGTGTCT 3', and 1 R of 5' CGCAGGGGGTGGGCGGTCACTCCA; 2L consisted of 5' GTGATCAAGCAGGCTGACTATGTG $3^{\prime}$ and 2R of 5' GCTGCTGGCCACCACGAAGATGAT 3'. The complementary sequences from the primers $1 \mathrm{~L}$ and $2 \mathrm{~L}$ were in intron 6 and exon 7 , respectively (27), and those for $1 R$ and $2 R$ were in exon 10 , with $1 L$ being $5^{\prime}$ to $2 L$ and $1 R$ being $3^{\prime}$ to $2 R$. Thus, the binding sites for $2 L$ and $2 R$ are nested within the segment amplified by $1 \mathrm{~L}$ and $1 R$, thereby enhancing the sensitivity and specificity of the PCR amplification as follows: 250 ng of genomic DNA were added to a $25 \mu$ l volume containing 30 pmol each of primers $1 \mathrm{~L}$ and $1 \mathrm{R}$ and 1.5 units of the heat stable DNA polymerase of Thermus aquaticus ( Taq polymerases; BRL, Gaithersburg, MD) (5). The buffers and conditions utilized for PCR were as previously described (5). On completion, $2 \mu \mathrm{l}$ of the reaction mix and $30 \mathrm{pmol}$ each of the nested primers $2 \mathrm{~L}$ and $2 \mathrm{R}$ were utilized for the second round of PCR amplification using conditions previously described (5). $2 \mu$ l of the nested PCR product were denatured in $0.4 \mathrm{M}$ sodium hydroxide and $25 \mathrm{mM}$ EDTA for 5 min at room temperature, dot blotted onto nylon filters (Hybond $\mathrm{N}+$; Amersham Corp, Arlington Heights, IL), and crosslinked to the filter by ultraviolet light. The filters were hybridized with $\gamma^{32} \mathrm{P}$ end-labeled

Table I. Clinical, Biochemical, Histological, and Immunocytochemistry Findings in 13 Patients with Acromegaly

\begin{tabular}{|c|c|c|c|c|c|c|c|c|c|c|c|c|c|}
\hline & \multicolumn{13}{|c|}{ Patient } \\
\hline & 1 & 2 & 3 & 4 & 5 & 6 & 7 & 8 & 9 & 10 & 11 & 12 & 13 \\
\hline Sex & $F$ & $\mathbf{M}$ & $\mathbf{M}$ & $\mathbf{M}$ & $\mathrm{F}$ & $\mathbf{M}$ & $\mathbf{M}$ & $F$ & $F$ & $F$ & $\mathbf{M}$ & $F$ & $F$ \\
\hline Age (years) & 38 & 65 & 40 & 34 & 23 & 20 & 42 & 24 & 46 & 46 & 23 & 57 & 60 \\
\hline \multicolumn{14}{|l|}{ Serum GH $(N<5 \mathrm{ng} / \mathrm{ml})$} \\
\hline prehypophysectomy & 70 & $>50$ & $>50$ & 24 & 113 & $>100$ & 45 & 40 & 50 & 50 & 40 & 29 & $>50$ \\
\hline posthypophysectomy & 13 & $<5$ & 11 & 11 & $<5$ & 30 & 6 & 6 & 7 & 6 & 10 & 12 & $<5$ \\
\hline Pituitary histology & $\mathrm{E}$ & $\mathrm{E}$ & $\mathbf{E}$ & C & $\mathrm{E}$ & - & $\mathrm{E}$ & - & $\mathrm{E}$ & $E+C$ & E & $\mathrm{E}+\mathrm{C}$ & $\mathrm{E}$ \\
\hline Immunocytochemistry & $\mathbf{S}$ & $\mathbf{S}$ & $\mathbf{S}$ & $S+L$ & $\mathbf{S}$ & $\mathbf{S}+\mathrm{L}$ & $\mathbf{S}$ & $\mathbf{S}+\mathrm{L}$ & $\mathbf{S}$ & $S+L$ & $\mathbf{S}$ & - & - \\
\hline
\end{tabular}

Pituitary histology: E, Eosinophil adenoma; C, Chromophobe adenoma; Immunochemistry: S, Somatotrophs; L, Lactotrophs. 
oligonucleotide probes, which were 20 bases in length and contained either the wild type (WT) sequence of arginine at position 201 (R201, codon sequence CGT) or a substitution of cysteine for arginine at position 201 ( R201C, codon sequence TGT), or a substitution of histidine for arginine at position $201(\mathrm{R} 201 \mathrm{H}$, codon sequence CAT), or the wild type sequence of glutamine at position 227 (Q227, codon sequence $(A G)$, or a substitution of arginine for glutamine at position 227 (Q227R, each on codon sequence CGG), or a substitution of leucine for glutamine at position 227 (Q227L, codon sequence CTG). The DNA sequences of these oligonucleotide probes, together with hybridization and washing conditions, were as previously described ( 5 , 28 ). The results of this allele-specific oligonucleotide analysis were confirmed by direct double-stranded DNA sequencing of the leukocyte and tumor DNA, using methods previously described (29).

\section{Results}

Allelic deletions in somatotrophinomas. 13 of the 14 DNA probes from chromosome 11 proved informative to varying degrees in the thirteen acromegalic patients from whom somatotrophinomas were obtained. A comparison of leukocyte-derived and tumor-derived RFLPs from chromosome 11 markers (Fig. 1) indicated a loss of alleles in somatotrophinomas from 5 of the 13 patients with acromegaly (patients $1,2,5$, 12, and 13). Fig. 2 shows the allelic deletions on chromosome 11 , identified with the use of the DNA probes PGA, PYGM, D11S97, and D1 1S147 in four patients. For example, an examination of the RFLPs at the PYGM locus obtained from the peripheral leukocytes and somatotrophinomas of patient 1 showed that digestion with the enzyme TaqI yielded two bands

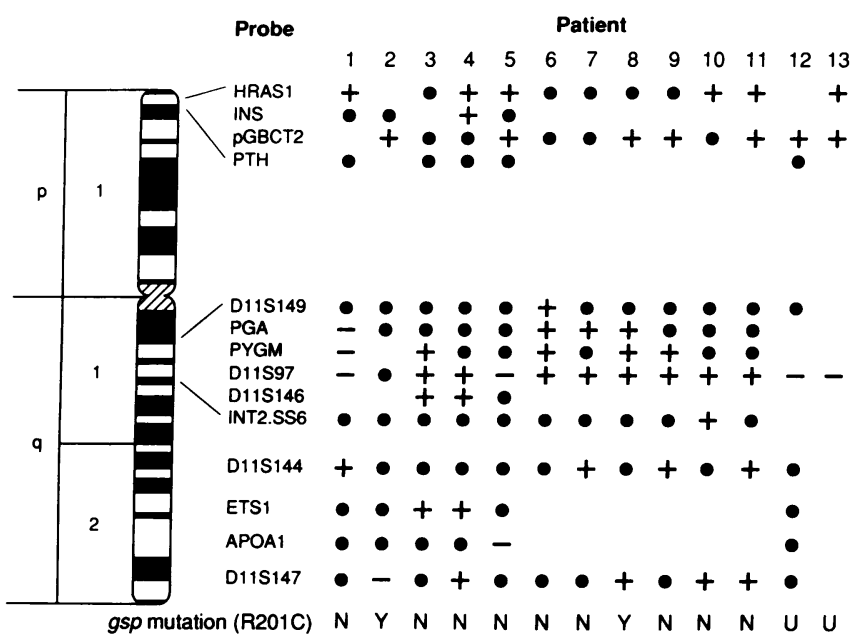

Figure 1. Analysis of alleles on chromosome 11 in DNA from leukocytes and somatotrophinomas from 13 patients (Table I). The leukocyte and somatotrophinoma alleles were determined as shown in Fig. 2 and 51 of the 128 leukocyte genotypes determined were heterozygous. The corresponding somatotrophinoma (tumor) genotypes indicated heterozygosity $(+)$ at 43 loci and allelic deletions $(-)$ at 8 loci. The 77 remaining homozygous loci $(\bullet)$ in the leukocytes were not studied in the tumors, as the small amounts of DNA obtained from some tumors limited the number of loci which could be examined. Allelic deletions ( - ) were detected in the somatotrophinomas from patients $1,2,5,12$, and 13. Gsp mutations were determined as shown in Fig. 4 and the presence ( $Y$, yes; $N$, no; $U$, unknown) of the $\mathrm{R} 201 \mathrm{C}$ mutation is indicated for each patient. The results reveal that the development of somatotrophinomas may be associated with allelic deletions of chromosome 11 and with gsp mutations. from the leukocyte of this patient, indicating leukocyte heterozygosity, whereas the tumor DNA had only the lower band, indicating a loss in heterozygosity. This loss of an allele, which is indicated by the arrow in Fig. 2, resulted from a loss of a region of the chromosome containing the marker gene PYGM; the complete absence of bands suggested that this abnormality had occurred within all the tumor cells studied and indicated a monoclonal origin of the tumor. Similar results were observed with the use of the probe PGA and the enzyme BglII, although the RFLPs are more complex (30) as the polymorphic largest

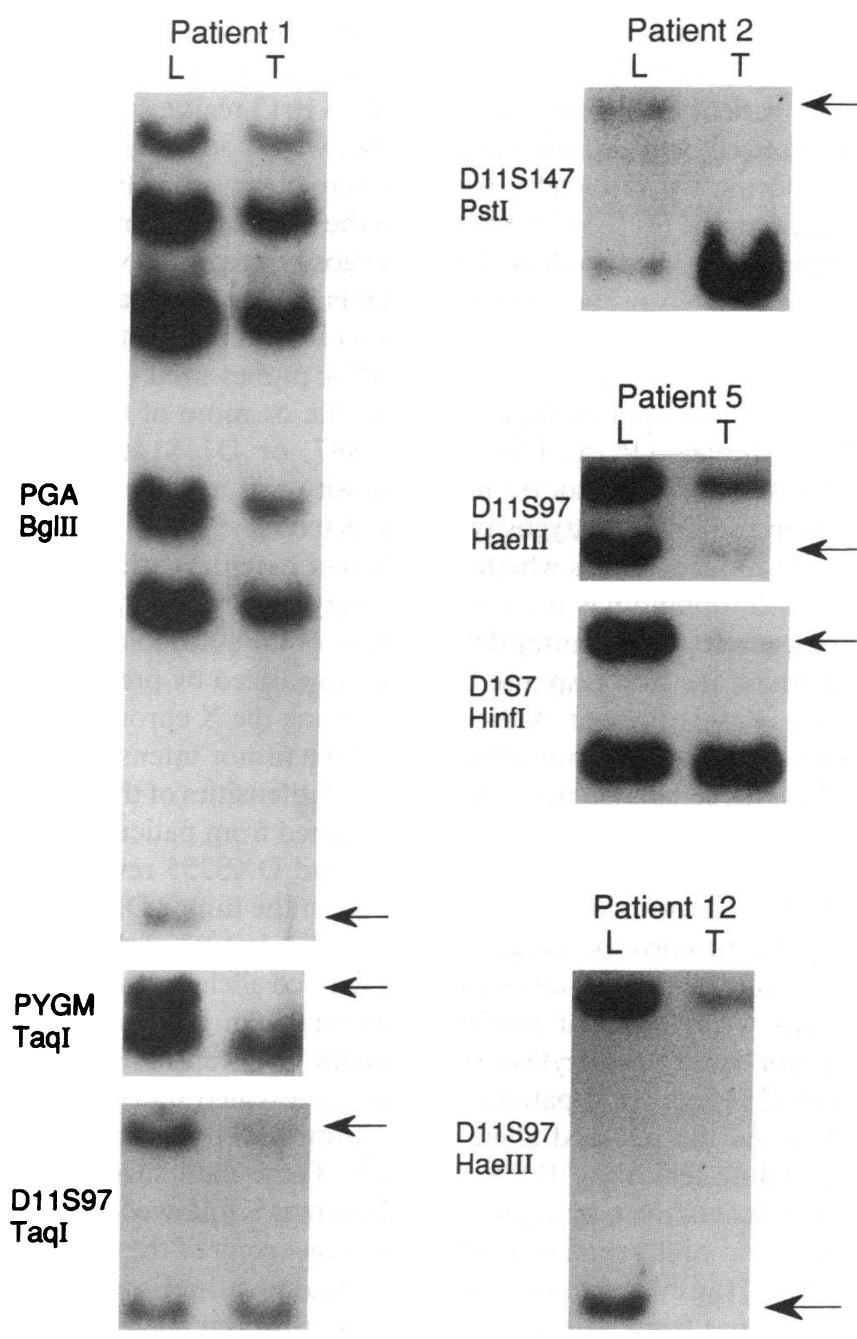

Figure 2. Allelic deletions on chromosome 11 and chromosome 1 in somatotrophinomas from four patients. The panels show some of the autoradiographs obtained from patients $1,2,5$, and 12 (Table I). Genomic DNA was obtained from each patient's peripheral blood leukocytes $(L)$ and somatotrophinoma tumor cells $(T)$ and digested with the restriction endonuclease (Bgl II, TaqI, PstI, HaeIII, or Hinf I) as indicated. Southern blot filters were prepared and hybridized with the probe indicated at the left of each panel (PGA, PYGM, D11S97, D1 1S147 or D1S7). Each probe is uniquely homologous to a particular region of human chromosome 11 (Fig. 1) or chromosome 1 and reveals variations in enzyme cleavage sites near its locus. These variations result in RFLPs, which are designated alleles. At each represented locus, the leukocytes are heterozygous whereas the tumor cells have lost one of the alleles, which is indicated by the arrow $(\leftarrow)$. These results demonstrate that allelic deletions on chromosome 11 are involved in the monoclonal development of somatotrophinomas. 
and the smallest bands are separated by 4 intervening constant bands; the results from patient 1 revealed that the tumor cells had lost the smaller polymorphic band, which is indicated by the arrow in Fig. 2. Chromosome 11 allele loss was also observed with the probes D11S97 and D11S147 in patients 1, 2, 5, and 12. As shown in Fig. 1, somatotrophinomas from five of the thirteen patients had loss of alleles identified by probes from the long arm of chromosome 11; patient 1 had a loss of alleles at 3 of 5 informative sites, patient 2 at 1 of 2 informative sites, patient 5 at 2 of 4 informative sites, patient 12 at 1 of 2 informative sites, and patient 13 at 1 of 3 informative sites. The region of allele loss common to 4 of the 5 tumors (patients 1,5 , 12 , and 13 ) involved $11 \mathrm{q} 13$, a region where the MEN1 gene has previously been localized $(11,12)$. In the remaining tumor from patient 2 , allele loss involving the $11 \mathrm{q} 13$ region could not be assessed as the leukocyte genotypes were homozygous and uninformative, but allelic deletions were observed with the telomere probe D1 1S147 from 1 lq. In the other eight somatotrophinomas studied, no loss of heterozygosity was found with the use of 14 DNA probes. In these patients (patients 3, 4, and 6 to 11 ), the leukocytes were homozygous (i.e., uninformative) for 4 out of 9 , to 9 out of 13 of the DNA probes used (Fig. 2). However, in each of these patients, one or more of the four DNA probes (PGA, PYGM, D11S97, or D11S146) from 11 q13 revealed leukocyte heterozygosity and at these loci no loss in tumor heterozygosity was detected.

In order to assess whether the loss of heterozygosity in the somatotrophinomas resulted in hemizygosity or homozygosity, quantitative scanning densitometry of the autoradiographs, in which the film response had been linearized by preflashing (31), was performed. Allele loss involving the X chromosome locus DXS255 was not observed and the tumor intensity ratio $\left(I_{\mathrm{rT}}\right)$ was calculated from the measured intensities of the alleles (Fig. 3). For example, the results obtained from patient 5 with the use of the DNA probes D11S97 and DXS255 reveal that the copy number of the retained allele in the tumor DNA relative to the corresponding leukocyte DNA is 1.97. Analysis of this patient's tumor- and leukocyte-derived alleles at the apoA 1 locus yielded similar results. In addition, an analysis of the tumor- and leukocyte-derived alleles at the D11S97 and DXS255 loci from patient 12 (Fig. 2) revealed that the ratio between the retained allele in the tumor DNA to the corresponding leukocyte DNA was 2.36. These data suggest that allele loss in these two somatotrophinomas is followed by reduplication of the remaining portion of one copy of the chromosome. However, an analysis of the remaining three somatotrophinomas from patients 1,2 , and 13 , in whom allele loss had been demonstrated (Fig. 1), did not confirm tumor homozygosity and the data from patient 1 were in keeping with tumor hemizygosity with a tumor/leukocyte allele ratio of less than 0.9. These limited data from a small number of somatotrophinomas indicate that $40 \%$ of somatotrophinomas lose part of one copy of chromosome 11 , and that in some tumors there may be a reduplication of the remaining regional copy of chromosome 11.

The specificity of these allelic deletions for chromosome 11 in the somatotrophinomas was assessed by examining for similar allele loss on 20 other autosomes, utilizing one DNA probe from each chromosome. 12 of the 20 DNA probes proved informative to varying degrees and allele loss was therefore limited to these loci, which were from chromosome $1 \mathrm{p} 35-\mathrm{p} 33,2 \mathrm{p}$,

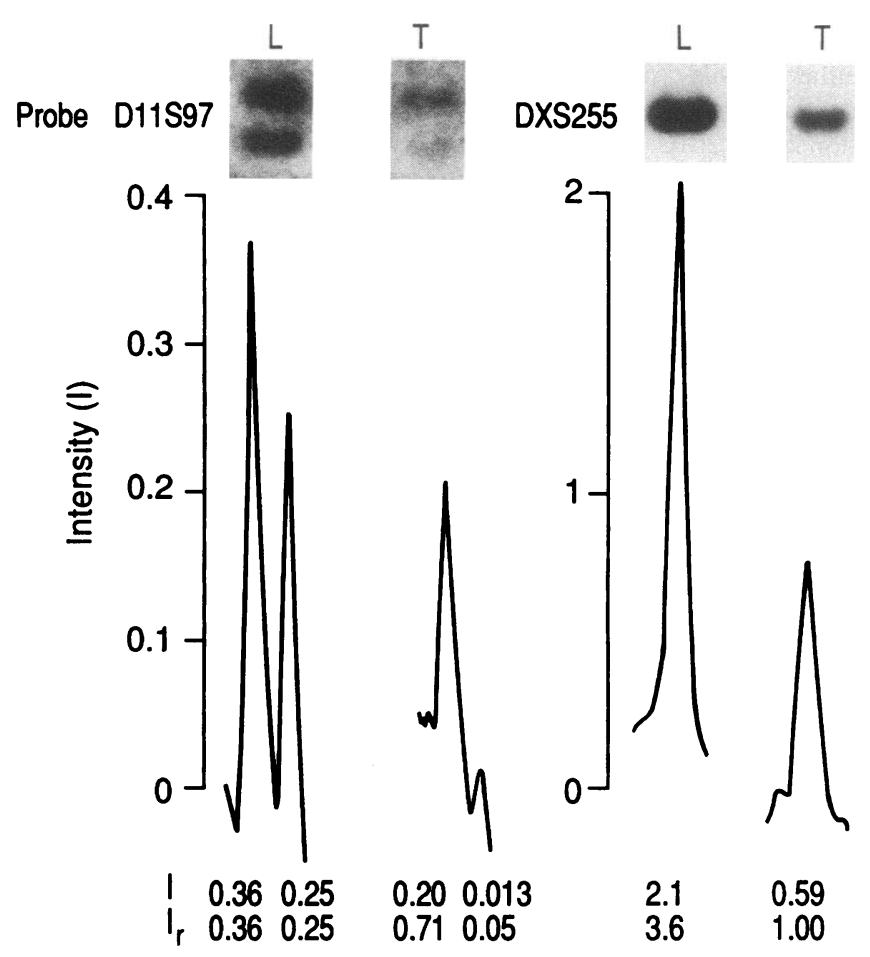

Figure 3. Densitometric scans are shown below the corresponding autoradiographs obtained using the probes D11S97 and DXS255 from the leukocyte $(L)$ and tumor ( $T$ ) DNA of patient 5 (Fig. 2). The intensity $(I)$ and the relative intensity $(I r)$ which corrects for differences in the amount of DNA of each band are indicated. The results of densitometric scanning confirm the findings of visual assessment, which indicated a loss of tumor heterozygosity. In addition, the relative intensity of the retained tumor allele is twice $(0.71$ $\div 0.36$ ) that of the corresponding leukocyte allele. Thus, the results of scanning densitometry suggest that in the tumor a reduplication of the retained chromosomal region has occurred, and led to tumor homozygosity in the somatotrophinoma of this patient.

3, 4p16.3, 5q35-qter, 7p22, 8, 9q34, 12q 24.3-qter, 13q12-21, $14 q 32$, and 17q. Allele loss which did not involve chromosome 11 was detected in only one somatotrophinoma. This allelic deletion was demonstrated in the tumor of patient 5 (Fig. 2) by the use of the probe D1S7, which has been localized to chromosome $1 \mathrm{p} 35-\mathrm{p} 33$. Thus, the somatotrophinoma of patient 5 was associated with allelic deletions of chromosomes 11 and 1 , while the somatotrophinomas of patients 1,2 , and 12 were associated with allele loss that specifically involved chromosome 11 . These results indicate that the observed allelic deletions of chromosome 11 in these somatotrophinomas are specific and not part of a generalized loss in these tumors.

Gsp mutations in somatotrophinomas. DNA from eleven of the thirteen somatotrophinomas from patients 1 to 11 (Fig. 1) was available for the investigation of the four tumor gsp mutations that are associated with somatotrophinomas $(4,5,28)$. The mutations involving arginine at position 201 , which have been designated $\mathrm{R} 201 \mathrm{C}$ and $\mathrm{R} 201 \mathrm{H}$, occur in exon 8, and those involving glutamine at position 227 , which have been designated Q227R and Q227L, occur in exon 9. A genomic fragment of DNA of 526 base pairs $(\mathrm{bp})$ containing the $3^{\prime}$ portion of exon 7 , the whole of exons 8 and 9 , and the $5^{\prime}$ portion of exon 10 was amplified by PCR from leukocyte and tumor 


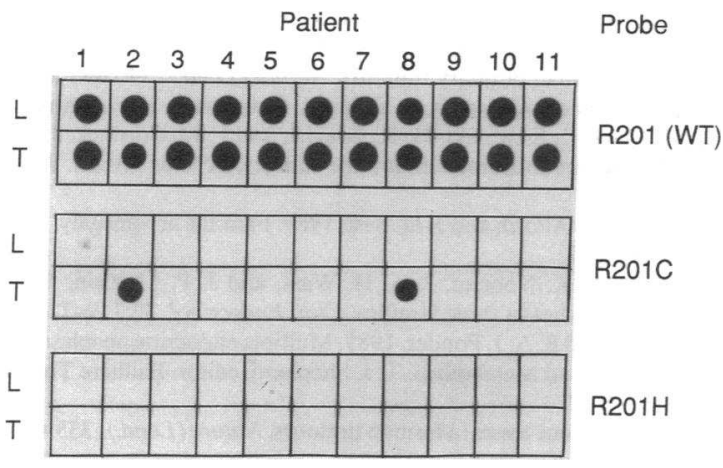

Figure 4. Analysis of $g s p$ mutations in the somatotrophinomas from patients 1 to 11 (Fig. 1). The results obtained by utilizing the allele-specific oligonucleotide probes R201(WT), R201C, and $\mathrm{R} 201 \mathrm{H}$ and the patients' leukocyte $(L)$ and tumor $(T)$ DNA are shown, and an analysis revealed abnormalities in the tumor DNA from patients 2 and 8 . These findings were confirmed by direct DNA sequence analysis.

DNA. The amplified DNA segments were bound to nylon filters and hybridized at high stringency (5) to radiolabeled oligonucleotide probes that either matched the WT sequence or contained specific single base substitutions. This method for identifying mutations is referred to as allele-specific oligonucleotide (ASO) hybridization, and the results of the analysis with WT R201 and mutant R201C and R201H oligonucleotide probes are shown in Fig. 4. Hybridization signals were obtained from the leukocyte and tumor DNA of all the patients when using the wild type oligonucleotide probe R201(WT). However, hybridization signals were obtained only from the tumor DNA of patients 2 and 8 when the mutant R201C probe was used, and no hybridization signals were obtained from either the leukocyte or tumor DNA when the mutant R201H was used. Thus, the somatotrophinoma DNA from patients 2 and 8 was associated with a $\mathrm{C} \rightarrow \mathrm{T}$ mutation in codon 201 (CGT), which resulted in a substitution of cysteine for arginine, whereas the leukocyte DNA from these patients, together with the leukocyte and tumor DNA from the remaining patients, was found not to contain mutant sequences but wild type (i.e., normal) $\mathrm{G}_{\mathrm{s}} \alpha$ sequences. These point mutations of codon 201 in exon 8 of the $G_{s} \alpha$ gene were confirmed by determining the DNA sequence of the amplified DNA segments obtained from the tumor and leukocytes of patients 2 and 8 (data not shown). An analysis with WT Q227 and mutant Q227R and Q227L oligonucleotide probes revealed no abnormalities in the tumor DNA from the 11 patients. Thus, gsp mutations in which cysteine had been substituted for arginine at position 201 were found to be associated with 2 of the 11 somatotrophinomas. One of these tumors (patient 2) was also found to be associated with allelic deletions of chromosome 11 (Fig. 1).

\section{Discussion}

The results of our study demonstrate that abnormalities of chromosome 11 and gsp mutations are associated with somatotrophinomas. The loss of alleles in these tumors, which were from patients with isolated acromegaly and from a patient in whom acromegaly was part of the MEN1 syndrome, indicates that the development of somatotrophinomas is monoclonal.
This finding is in agreement with those of previous studies, which have investigated $\mathrm{X}$ chromosome inactivation to reveal that somatotrophinomas together with prolactinomas, corticotrophinomas, and nonfunctioning pituitary tumors are monoclonal in origin $(32,33)$. In addition, a study of one MEN1 somatotrophinoma (34) has also indicated monoclonality by demonstrating allelic deletions of chromosome 11. However, another study (13) of 10 somatotrophinomas ( 9 non-MEN 1 and 1 MEN1) did not detect such allele loss and a direct comparison with our study, which revealed allelic deletions of chromosome 11 in non-MEN1 and MEN1 somatotrophinomas, requires cautious interpretation, as important different DNA probes were used. For example, we selected to use the DNA probe D11S97 as it is highly polymorphic (21) and located in the region of the MEN1 gene $(35,36)$, thereby optimizing our chance for the detection of allelic deletions in this region. D11S97, which was not used in the previous study (13), proved to be highly informative in our study by revealing leukocyte heterozygosity in 12 of the 13 patients, and by detecting a loss of heterozygosity in 4 of the 5 tumors that were associated with allelic deletions of chromosome 11 (Fig. 1). Thus, our use of such a highly polymorphic DNA probe from the MEN1 region helped to facilitate the detection of allele loss in somatotrophinomas. Our study, which identified allele deletions involving the long arm of chromosome 11 , indicated that the monoclonal development of 3 of the 5 tumors was associated with localized deletions resulting in hemizygosity, and that in 2 of the 5 tumors allele loss was associated with homozygosity due to a duplication of the surviving mutant chromosome. Karyotype analysis, which we have not performed, in the case of somatotrophs will help to elucidate these genetic abnormalities, which are analogous to those reported in retinoblastoma (3) and colorectal carcinoma (37). Thus, our findings are consistent with the hypothesis that recessive mutations in tumor suppressor genes (38) are associated with the development of somatotrophinomas. In addition, the results of our study of somatotrophinomas resemble those reported in MEN1 and non-MEN1 parathyroid tumors (12-14), MEN1 insulinomas (11), one MEN1 somatotrophinoma (34), and non-MEN1 prolactinomas (13), and these observations together suggest that the genetic abnormalities involved in the development of somatotrophinomas, prolactinomas, parathyroid, and pancreatic $\beta$-islet cell tumors may be similar.

Our study did not detect the loss of alleles in somatotrophinomas from eight patients. Tumor size, histological features, and circulating GH concentrations in these patients did not notably differ from those in whom deletions were found. Similar findings have been reported from a previous study of ten somatotrophinomas in which chromosome 11 allelic deletions were not detected (13). The failure to detect a loss of heterozygosity in these studies may partly be attributable to the uninformativeness-i.e., the homozygosity-of the peripheral leukocytes for many of the probes used. However, leukocyte heterozygosity was revealed in our 8 patients (patients 3,4 and 6-11) at one or more of the loci in 11 q13 (Fig. 1). The absence of allele loss in these somatotrophinomas may reflect a limitation of the current techniques to detect small focal abnormalities. Alternatively, this lack of allele loss may indicate a heterogenous origin for the tumors or the different stages-i.e., multiple steps-that occur in tumor development and progression. Allele loss involving chromosome 1 was observed in one soma- 
totrophinoma (Fig. 2) and similar abnormalities involving chromosomes 1 and 4 have been reported in two other somatotrophinomas (13). These findings suggest that different tumor suppressor genes located on chromosomes 11,1 , and 4 may be involved in the multistep progression of somatotrophinomas analogous to that reported for colorectal carcinomas (39-41). In addition, the commoner occurrence of allele loss on chromosome 11 in these tumors suggests that an allelic deletion on chromosome 11 may be an early event in the development of somatotrophinomas.

Our results, which indicate the involvement of a recessive tumor suppressor gene on chromosome 11 in the development of somatotrophinomas, reveal an additional etiology to that previously reported for a subset of somatotrophinomas $(4,5)$. In these tumors, mutations of the gene encoding the $\alpha$ chain of the Gs protein, which has been localized to chromosome 20 (42), behaved like dominantly acting oncogenes. Our investigation for $\mathrm{G}_{\mathrm{s}} \alpha$ mutations in 11 of 13 patients with somatotrophinomas revealed $g s p$ mutations in two tumors (Fig. 4). One of these tumors was also associated with allelic deletions on chromosome 11 (Fig. 1). Our combined results may help to elucidate further the roles of these two mutations, and a genetic model for the development of somatotrophinomas may involve the following possibilities: (a) tumorigenesis may be associated with either an allelic deletion on chromosome 11 or a mutation of $\mathrm{G}_{\mathrm{s}} \alpha ;(b)$ an early mutation of $\mathrm{G}_{\mathrm{s}} \alpha$ may initiate a clonal proliferation during which a mitotic disjunction involving an allele loss of chromosome 11 occurs; $(c)$ an allelic deletion of chromosome 11 precedes $\mathrm{a}_{\mathrm{s}} \alpha$ mutation, which would then convert a small adenoma to a larger proliferative one by enhancing clonal expansion of the cell with the allelic deletion; $(d)$ the order in which these mutations occur may not be invariant, and the accumulation of these genetic abnormalities may be more important in the development and progression of the tumor. The results of our study, which have identified the occurrence in somatotrophinomas of either allelic deletions of chromosome 11 or of $g s p$ mutations, provide support for these genetic models. Further detailed analysis of our proposed models for the development of somatotrophinomas, which are similar to those reported for colorectal tumors $(40,41)$, will help to elucidate the roles of the dominant and recessive oncogenes associated with these growth hormone-secreting pituitary tumors.

\section{Acknowledgments}

We are grateful to Professors R. K. Craig, A. J. Jeffreys, and J. Scott, and to Drs. D. Cohen, I. Craig, C. Dickson, and G. Peters for the gift of probes; to the American Type Culture Collection (ATCC) and the Human Genome Mapping Project (Medical Research Council) for DNA probes; to Dr. M. S. Stoll for help with the autodensitometry scanning; and to Ms. L. Sargeant for typing the manuscript.

This research is supported by the Medical Research Council, UK, to which we express our appreciation.

\section{References}

1. Varmus, H. E. 1984. The molecular genetics of cellular oncogenes. Annu. Rev. Genet. 18:533-612.

2. Friend, S. H., T. P. Dryja, and R. A. Weinberg. 1988. Oncogenes and tumor-suppressor genes. N. Engl. J. Med. 318:618-622.

3. Hansen, M. F., and H. Plonait. 1988. Retinoblastoma and the progression of tumour genetics. Trend. Genet. 4:125-128.
4. Landis, C. A., S. B. Masters, A. Spada, A. M. Pace, H. R. Bourne, and L. Vallar. 1989. GTPase inhibiting mutations activate the $\alpha$ chain of Gs and stimulate adenyl cyclase in human pituitary tumours. Nature (Lond.). 340:692-696.

5. Lyons, J., C. A. Landis, G. Harsh, L. Vallar, K. Grünewald, H. Feichtinger, Q-Y. Duh, O. H. Clark, E. Kawasaki, H. R. Bourne, and F. McCormick. 1990. Two $G$ protein oncogenes in human endocrine tumors. Science (Wash. DC). 249:655-659.

6. Pestell, R. G., F. P. Alford, and J. D. Best. 1989. Familial acromegaly. Acta Endocrinol. 121:286-289.

7. McCarthy, M. I., K. Noonan, J. A. H. Wass, and J. P. Monson. 1990. Familial acromegaly: studies in three families. Clin. Endocrinol. 32:719-728.

8. Thakker, R. V., and B. A. J. Ponder. 1989. Multiple endocrine neoplasia. In Clinical Endocrinology and Metabolism. T. J. Shepherd, editor. Baillière Tindall Ltd, London. 1031-1067.

9. Ponder, B. 1988. Gene losses in human tumours. Nature (Lond.). 335:400402.

10. Khosla, S., V. M. Patel, I. D. Hay, D. J. Schaid, C. S. Grant, J. A. van Heerden, and S. N. Thibodeau. 1991. Loss of heterozygosity suggests multiple genetic alterations in pheochromocytomas and medullary thyroid carcinomas. $J$. Clin. Invest. 87:1691-1699.

11. Larsson, C., B. Skogseld, K. Oberg, Y. Nakamura, and M. C. Nordenskjold. 1988. Multiple endocrine neoplasia type 1 gene maps to chromosome 11 and is lost in insulinoma. Nature (Lond.). 332:85-87.

12. Thakker, R. V., P. Bouloux, C. Wooding, K. Chotai, P. M. Broad, N. K Spurr, G. M. Besser, and J. L. H. O'Riordan. 1989. Association of parathyroid tumors in multiple endocrine neoplasia type 1 with loss of alleles on chromosome 11. N. Engl. J. Med. 321:218-224.

13. Bystrom, C., C. Larsson, C. Blomberg, K. Sandelin, U. Falkmer, B. Skogseid, K. Oberg, S. Werner, and M. Nordenskjold. 1990. Localization of the MEN1 gene to a small region within chromosome 11 q13 by deletion mapping in tumors. Proc. Natl. Acad. Sci. USA. 87:1968-1972.

14. Friedman, E., K. Sakaguchi, A. E. Bale, A. Falchetti, E. Streeten, M. B. Zimering, L. S. Weinstein, J. A. Norton, G. D. Aurbach, A. M. Spiegel, and S. J. Marx. 1989. Clonality of parathyroid tumors in familial multiple endocrine neoplasia type 1. N. Engl. J. Med. 321:213-224.

15. Bale, A. E., J. A. Norton, E. L. Wong, J. S. Fryburg, P. N. Maton, E. H. Oldfield, E. Streeten, G. D. Aurbach, M. L. Brandi, and E. Friedman. 1991. Allelic loss on chromosome 11 in hereditary and sporadic tumors related to familial multiple endocrine neoplasia type 1. Cancer Res. 51:1154-1157.

16. Kunkel, L. M., K. D. Smith, S. H. Boyer, D. S. Borgaonkar, S. S. Wachtel, O. J. Miller, W. R. Breg, H. W. Jones, and J. M. Rary. 1977. Analysis of human Y chromosome specific reiterated DNA in chromosome variants. Proc. Natl. Acad. Sci. USA. 74:1245-1249.

17. Aldridge, J., L. Kundel, and G. Bruns. 1984. A strategy to reveal high frequency RFLPs along the human X chromosome. Am. J. Hum. Genet. 36:546564.

18. Southern, E. M. 1975. Detection of specific sequences among DNA fragments separated by gel electrophoresis. J. Mol. Biol. 98:503-517.

19. Rigby, P. W. J., M. Dieckmann, C. Rhodes, and P. Berg. 1977. Labelling deoxyribonucleic acid by nick translation with DNA polymerase I. J. Mol. Biol. 113:237-251.

20. Feinberg, A. P., and B. Vogelstein. 1983. A technique for radiolabelling DNA restriction endonuclease fragments to high specific activity. Anal. Biochem. 132:6-13.

21. Williamson, R., A. Bowcock, K. Kidd, P. Pearson, J. Schmidtke, P. Ceverha, M. Chipperfield, D. N. Cooper, C. Coutelle, J. Hewitt, et al. 1991. Report of the DNA Committee and catalogues of cloned and mapped genes, markers formulated for PCR and DNA polymorphisms. Cytogenet. Cell. Genet. 58:11901832.

22. Thakker, R. V., K. E. Davies, M. P. Whyte, C. Wooding, and J. L. H. O'Riordan. 1990. Mapping the gene causing X-linked recessive idiopathic hypoparathyroidism to Xq26-Xq27 by linkage studies. J. Clin. Invest. 86:40-45.

23. Fraser, N. J., Y. Boyd, G. G. Brownlee, and I. W. Craig. 1987. Multi-allelic RFLP for M27 $\beta$, an anonymous single copy genomic clone at Xp11.3-Xcen (HGM9 provisional no. DXS255). Nucleic Acids Res. 15:9616.

24. Seizinger, B. R., H. P. Klinger, C. Junien, Y. Nakamura, M. Le Beau, W. Cavanee, B. Emmanuel, B. Ponder, S. Naylor, F. Mitelman, et al. 1991. Report of the committee on chromosome and gene loss in human neoplasia. Cytogenet. Cell Genet. 58:1080-1096.

25. Fearon, E. R., B. Vogelstein, and A. Feinberg. 1984. Somatic deletion and duplication of genes on chromosome 11 in Wilms' tumour. Nature (Lond.). 309:176-178.

26. Saiki, R. K., D. H. Gelfand, and S. Stoffel. 1988. Primer-directed enzymatic amplification of DNA with a thermostable DNA polymerase. Science (Wash. DC). 239:487-491.

27. Kozasa, T., H. Ito, T. Tsukamoto, and Y. Kaziro. 1988. Isolation and characterization of the human $\mathrm{G}_{3} \alpha$ gene. Proc. Natl. Acad. Sci. USA. 85:20812085.

28. Clementi, E., N. Malgaretti, J. Meldolesi, and R. Taramelli. 1990. A new 
constitutively activating mutation of the Gs protein $\alpha$ subunit-gsp oncogene is found in human pituitary tumours. Oncogene. 5:1059-1061.

29. Parkinson, D. B., and R. V. Thakker. 1992. A donor splice site mutation in the parathyroid hormone gene is associated with autosomal recessive hypoparathyroidism. Nature Genet. 1:149-152.

30. Boudi, F. H., R. A. Lothe, and R. T. Taggart. 1990. Human pepsinogen A (PGA): an informative gene complex located at 11q13. Hum. Genet. 84:293295.

31. Laskey, R. A., and A. D. Mills. 1975. Quantitative film detection of ${ }^{3} \mathrm{H}$ and ${ }^{14} \mathrm{C}$ in polyacrylamide gels by fluorography. Eur. J. Biochem. 56:335-341.

32. Alexander, J. M., B. M. K. Biller, H. Bikkal, N. T. Zervas, A. Arnold, and A. Klibanski. 1990. Clinically nonfunctioning pituitary tumors are monoclonal in origin. J. Clin. Invest. 86:336-340.

33. Herman, V., J. Fagin, R. Gonsky, K. Kovacs, and S. Melmed. 1990. Clonal origin of pituitary adenomas. J. Clin. Endocrinol. 71:1427-1433.

34. Yoshimoto, K., H. Iwahana, K. Kubo, S. Saito, and M. Itakura. 1991. Allele loss on chromosome 11 in a pituitary tumor from a patient with multiple endocrine neoplasia type 1. Jpn. J. Cancer Res. 82:886-889.

35. Larsson, C., J. Shepherd, Y. Nakamura, C. Blomberg, G. Weber, B. Werelius, N. Hayward, B. Teh, T. Tokino, B. Seizinger, et al. 1992. Predictive testing for multiple endocrine neoplasia type 1 using DNA polymorphisms. J. Clin. Invest. 89:1344-1349.

36. Thakker, R. V., C. Wooding, J. T. Pang, B. Farren, B. Harding, D. C. Anderson, G. M. Besser, P. Bouloux, D. P. Brenton, K. D. Buchanan, et al. 1993. Linkage analysis of 7 polymorphic markers at chromosome 11 p11.2-11q13 in 27 multiple endocrine neoplasia type 1 families. Ann. Hum. Genet. In press.

37. Solomon, E., R. Voss, and V. Hall. 1987. Chromosome 5 allele loss in human colorectal carcinomas. Nature (Lond.). 328:616-619.

38. Knudson, A. G., L. C. Strong, and D. E. Anderson. 1973. Hereditary and cancer in man. Prog. Med. Genet. 9:113-158.

39. Vogelstein, B., E. R. Fearon, and S. R. Hamilton. 1988. Genetic alternations during colorectal-tumor development. N. Engl. J. Med. 319:525-532.

40. Stanbridge, E. J. 1990. Identifying tumor suppressor genes in human colorectal cancer. Science (Wash. DC). 247:12-13.

41. Fearon, E. R., and B. Vogelstein. 1990. A genetic model for colorectal tumorigenesis. Cell. 61:759-767.

42. Blatt, C., P. Eversole-Cire, V. H. Cohn, S. Zollman, R. E. K. Fournier, L. T. Mohandas, M. Nesbitt, T. Lugo, D. T. Jones, R. R. Reed, et al. 1988. Chromosomal localization of genes encoding guanine nucleotide-binding protein subunits in mouse and human. Proc. Natl. Acad. Sci. USA. 85:7642-7646. 